Setyo Purwoto dan Joko Sutrisno : Pengolahan Air Tanah Berbasis Treatment Ferrolite, ManganeseZeolite, dan IonExchange

\title{
PENGOLAHAN AIR TANAH BERBASIS TREATMENT Ferrolite, Manganese Zeolite, dan Ion Exchange
}

\author{
Setyo Purwoto ${ }^{1)}$ dan Joko Sutrisno ${ }^{2)}$ \\ 1) dan ${ }^{2)}$ Program Studi Teknik Lingkungan, Fakultas Teknik Sipil dan Perencanaan \\ Universitas PGRI Adi Buana (UNIPA) Surabaya \\ Email : setyopurwoto.enviro@gmail.com
}

\begin{abstract}
Abstrak
Fenomena cemaran air tanah saat ini semakin tinggi, sehingga dalam hal kriteria sebagai air bersih semakin kurang terpenuhi, karena air bersih layak konsumsi mempunyai standar persyaratan tertentu yakni persyaratan fisis, kimiawi, dan bakteriologis dimana syarat tersebut merupakan satu kesatuan. Air tanah di kawasan pesisir banyak dijumpai tingkat salinitasnya tinggi, sering pula diikiuti dengan kekeruhan yang tinggi, atau mengandung kesadahan berlebih, juga zat Besi (Fe) dan Mangan (Mn) yang cukup besar. Pada Penelitian pendahuluan, sampel air tanah di daerah Menanggal Surabaya mengandung ; Warna 75 Unit PtCo sedangkan (NAB 50), Kekeruhan 33.30 Skala NTU (NAB 25), Besi $2.46 \mathrm{mg} / \mathrm{L} \mathrm{Fe} \mathrm{(NAB} \mathrm{1),} \mathrm{Mangan} 3.25 \mathrm{mg} / \mathrm{L} \mathrm{Mn} \mathrm{(NAB} \mathrm{0.5),} \mathrm{Deterjen}$ $0.56 \mathrm{mg} / \mathrm{L}$ (NAB 0.5). Salinitas air sumur di daerah tertentu mencapai 6000 ppm. Mengacu pada penelitian terdahulu dan penelitian pendahuluan,maka untuk mengatasi masalah di atas dapat dilakukan dengan treatment ferrolite, manganesezeolite, dan ionexchange.Metode yang digunakan dalam penelitian ini adalah metode eksperimen laboratorium berupa rangkaian bath reactor yang mengacu pada perhitungan kriteria desain, kemudian sebagai justifikasi penelitian dilakukan uji lab hasil penelitian menurut kriteria parameter air bersih (Permenkes RI No.416/Menkes/ Per/IX/1990).Manfaat dan tujuan dari hasil penelitian ini adalah : guna mengetahui removal parameter air bersih pada pengolahan air tanah menggunakan treatment ferrolite, manganesezeolite , dan ionexchange.

Temuan dalam penggunaan treatment ferrolite, manganese zeolite, dan ion exchanger berupa resin anion dan resin kation pada air tanah mampu meremoval kandungan beban kekeruhan, warna, dan logam logam Besi, Kromium, serta Mangan hingga menjadi kriteria parameter air bersih mengacu pada permenkes nomor 416/Menkes/Per/IX/1990.
\end{abstract}

Kata Kunci ; water treatment; Ferrolite; manganesezeolite; ionexchange

\begin{abstract}
The phenomenon of groundwater contamination is increasingly high, so in terms of the criteria as clean water increasingly less satisfied, because the potable water consumption has certain requirements including physical requirement, chemical, and bacteriological where the requirement is one unit. The Groundwater in coastal areas are often found in high levels of salinity, often followed by high turbidity, or contain excessive hardness, also iron (Fe) and Manganese (Mn) that is quite large. In the preliminary study, groundwater samples in Menanggal Surabaya containing; Color 75

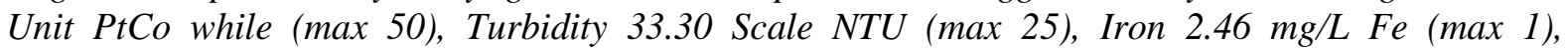
Manganese $3.25 \mathrm{mg} / \mathrm{L} \mathrm{Mn}(\max 0.5)$, Detergents $0.56 \mathrm{mg} / \mathrm{L}$ ( $\max 0.5)$. The Salinity of wells water in certain areas reached $6000 \mathrm{ppm}$. Referring to previous studies and preliminary research, to solve problems above can be done with treatment of ferrolite, manganese zeolite, and ion exchange. The method used in this research is a series of laboratory experiments bath reactor which refers to the calculation of design criteria, then as the research justification tested lab research results according to the criteria of clean water parameters (Permenkes RI 416/Menkes/Per/IX /1990). The Benefits and objectives of this research results are: In order to know the parameters of clean water on groundwater treatment using a treatment of ferrolite, manganese zeolite, and ion exchange.

The findings in using of treatment ferrolite, manganese zeolite, and ion exchanger as anion resin and cation resin in groundwater able to remove content of load turbidity, color, and many metal iron, chromium, and manganese up to be the criteria of clean water parameters refers to permenkes No. 416/Menkes/ Per/IX/1990.
\end{abstract}

Keywords ; water treatment; Ferrolite; manganese zeolite; ion exchange 


\section{PENDAHULUAN}

Air bersih layak konsumsi mempunyai standar persyaratan tertentu yakni ; persyaratan fisis, kimiawi, dan bakteriologis, dimana syarat tersebut merupakan satu kesatuan. Jadi jika ada satu saja parameter yang tidak memenuhi syarat, maka air tesebut bukan kriteria air bersih yang layak untuk dikonsumsi. Air tanah banyak dijumpai kadar salinitasnya tinggi terutama di kawasan pesisir, tingkat kekeruhan yang tinggi, sering pula mengandung kesadahan, serta adanya zat Besi $(\mathrm{Fe})$ dan Mangan $(\mathrm{Mn})$ yang cukup besar. Adanya kandungan $\mathrm{Fe}$ dan $\mathrm{Mn}$ dalam air menyebabkan warna air tersebut berubah menjadi kuning-coklat setelah beberapa saat kontak dengan udara. Disamping dapat mengganggu kesehatan juga menimbulkan bau yang kurang enak serta menyebabkan warna kuning pada diding bak serta bercak-bercak kuning pada pakaian.

Pada penelitian pendahuluan, sampel air tanah di daerah Menanggal Surabaya mengandung warna 75 Unit PtCo sedangkan (NAB 50), Kekeruhan 33.30 Skala NTU (NAB 25), Besi $2.46 \mathrm{mg} / \mathrm{L} \mathrm{Fe}$ (NAB 1), Mangan 3.25 mg/L Mn (NAB 0.5), Deterjen $0.56 \mathrm{mg} / \mathrm{L} \quad$ (NAB 0.5) (NAB menurut Permenkes RI No.416/Menkes/Per/IX/1990). Salinitas air sumur di daerah Kenjeran Surabaya mencapai 6000 ppm (Purwoto, S., 2008)

Menurut Said (1999), cara untuk menghilangkan kesadahan zat Besi dan Mangan dalam air, diantaranyamenggunakan treatment Zeolite, Resin Sintetis. Menurut Purwoto, S., (2014), banyak parameter air bersih yang berhasil diremoval dengan menggunakan treatment ; sediment Poly Propylene, Carbon Block, Manganese Zeolite, Ion Exchange, dan Reverse Osmosis (RO).

Kriteria air bersih diantaranya adalah jernih, tidak berwarna, rasanya tawar, tidak berbau, $\mathrm{pH}$ sekitar 6,5 - 8,5, tidak mengandung zat kimia beracun seperti arsen, timbal, nitrat, senyawa raksa, senyawa sulfida, senyawa fenolik, amoniak serta bahan radioaktif, tingkat kesadahannya rendah, tidak boleh mengandung bakteri patogen seperti Escheria coli .

Batasan penelitian dalam penelitian ini adalah removal parameter air bersih pada air tanah menggunakan perlakuan Ferrolite, Manganese Zeolite, dan Ion Exchange.
Alasan logis sebagai hipotesis, bahwa " Setelah dilakukan treatment Ferrolite, Manganese Zeolite, dan Ion Exchange pada pengolahan air tanah, maka beberapa parameter air bersih dapat mengalami penurunan"

Model teknologi pengolahan air menggunakan Treatment Ferrolite, Manganese Zeolite, dan Ion Exchange ini bertujuan untuk menurunkan beberapa parameter air bersih dalam air tanah, yang bermanfaat untuk meningkatkan kualitas air tanah.

\section{Kriteria Air Bersih}

1. Jernih atau tidak keruh. Kekeruhan pada air biasanya disebabkan oleh adanya butirbutir tanah liat yang sangat halus. Semakin keruh menunjukkan semakin banyak butirbutir tanah dan kotoran yang terkandung di dalamnya.

2. Tidak berwarna. Air yang berwarna berarti mengandung bahan-bahan lain berbahaya bagi kesehatan, misalnya pada air rawa berwarna kuning, air buangan dari pabrik, selokan, air sumur yang tercemar dan lain-lain.

3. Rasanya tawar. Air yang terasa asam, manis, pahit, atau asin menunjukan bahwa kualitas air tersebut tidak baik. Rasa asin disebabkan adanya garam-garam tertentu yang larut dalam air, sedangkan rasa asam diakibatkan adanya asam organik maupun asam anorganik.

4. Tidak berbau. Air yang baik memiliki ciri tidak berbau bila dicium dari jauh maupun dari dekat. Air yang berbau busuk mengandung bahan-bahan organik yang sedang didekomposisi (diuraikan) oleh mikroorganisme air.

5. Derajat keasaman $(p H)$ nya netral sekitar $6,5-8,5$. Air yang pHnya rendah akan terasa asam, sedangkan bila pHnya tinggi terasa pahit. Contoh air alam yang terasa asam adalah air gambut (rawa)

6. Tidak mengandug zat kimia beracun, misalnya arsen, timbal, nitrat, senyawa raksa, senyawa sulfida, senyawa fenolik, amoniak serta bahan radioaktif.

7. Kesadahannya rendah. Kesadahan air dapat diakibatkan oleh kandungan ion kalsium $\left(\mathrm{Ca}^{2+}\right)$ dan magnesium $\left(\mathrm{Mg}^{2+}\right)$. Hal ini dapat dilihat bila sabun atau deterjen yang digunakan sukar berbusa dan di bagian dasar peralatan yang dipergunakan untuk merebus air terdapat kerak atau endapan. Air sadah 
dapat juga mengandung ion-ion Mangan $\left(\mathrm{Mn}^{2+}\right)$ dan besi $\left(\mathrm{Fe}^{2+}\right)$ yang memberikan rasa anyir pada air dan berbau, serta akan menimbulkan noda-noda kuning kecoklatanpada peralatan dan pakaian yang dicuci. Meskipun ion kalsium, ion magnesium, ion besi dan ion mangan diperlukan oleh tubuh kita. Air sadah yang banyak mengandung ionion tersebut tidak baik untuk dikonsumsi. Karena dalam jangka panjang akan menimbulkan kerusakan pada ginjal, dan hati. Tubuh kita hanya memerlukan ion-ion tersebut dalam jumlah yang sangat sedikit sedikit sekali. Kalsium untuk pertumbuhan tulang dan gigi, mangan dan magnesium merupakan zat yang membantu kerja enzim, besi dibutuhkan untuk pembentukan sel darah merah.Batas kadar ion besi yang diizinkan terdapat di dalam air minum hanya sebesar 0,1 sampai 1 ppm $(\mathrm{ppm}=$ part per million, $1 \mathrm{ppm}=1$ mgr/1liter). Untuk ion mangan ; 0,005 - 0,5 ppm, ion kalsium : $75-200 \mathrm{ppm}$ dan ion magnesium : $30-150 \mathrm{ppm}$.

8. Tidak boleh mengandung bakteri patogen seperti Escheria coli, yaitu bakteri yang biasa terdapat dalam tinja atau kotoran, serta bakteri-bakteri lain yang dapat menyebabkan penyakit usus dan limpa, yaitu kolera, typhus, paratyphus, dan hepatitis. Dengan memasak air terlebih dahulu hingga mendidih, bakteri tersebut akan mati.

\section{Filter atau Saringan}

Digunakannya media filter atau saringan, berfungsi untuk memisahkan campuran solida likuida dengan media porous atau material porous lainnya guna memisahkan sebanyak mungkin padatan tersuspensi yang paling halus. Penyaringan ini merupakan proses pemisahan antara padatan atau koloid dengan cairan, dimana prosesnya dilakukan sebagai proses awal (primary treatment). Saringan kasar mampu menahan material tersuspensi dengan penetrasi partikel yang cukup dalam, sehingga saringan kasar mampu menyimpan lumpur dengan kapasitas yang tinggi. (Kusnaedi., 1995).

\section{Ferrolite}

Fungsi ferrolite adalah untuk menghilangkan kandungan besi tingkat tinggi $(\mathrm{Fe})$, bau besi yang menyengat, Mangan $\left(\mathrm{Mn}^{++}\right)$, warna kuning di air tanah atau air PDAM atau air gunung.
Pemakaian ferrolite:

1) Kandungan besi yang bisa diatasi oleh ferrolite adalah maksimal $20 \mathrm{ppm}$ atau kurang sedangkan kandungan $\mathrm{KMnO}_{4}$ ( mangan) adalah $15 \mathrm{ppm}$ dan $\mathrm{pH}$ nya $>6,5$. Jika tidak sesuai kondisi diatas, bisa dilakukan pre treatment dengan cara oksidasi agar kadar besi di bawah 20 ppm, pengaturan ph agar diatas 6,5 dll.

2) Bentuk butiran ferrolite memiliki keunggulan berpori sehingga mudah menyerap Besi dan Mangan dan sangat stabil sebagai filter media baik secara fisik maupun kimia

3) Bahan dari pasir yang memiliki kandungan silika berkualitas dan mengandung silika tinggi

4) Kelebihan ferrolite saat beroperasi:a)waktu aktivasi media untuk trial pertama sangat mudah dan sangat cepat, b)waktu cucinya juga sangat singkat dibanding media filter lainnya, c)kecuali kasus khusus, umumnya tidak perlu pre treatment, d)kecepatan air bisa $10-30 \mathrm{~m} 3 / \mathrm{h}$ dimana ini merupakan $2 \mathrm{x}$ kecepatan rata-rata filter umumnya, e)koagulan tidak diperlukan dan ini membantu mengurangi biaya, f)hanya periode tertentu mesti di cuci dan tidak perlu dilakukan regenerasi dengan bahan kimia

\section{Manganese zeolite}

Zeolit umumnya didefinisikan sebagai kristal alumina silika yang berstruktur tiga dimensi, yang terbentuk dari tetrahedral alumina dan silika dengan rongga-rongga di dalam yang berisi ion-ion logam, biasanya alkali atau alkali tanah dan molekul air yang dapat bergerak bebas. Secara empiris, rumus molekul zeolit adalah $\mathrm{M}_{\mathrm{x} / \mathrm{n}} \cdot\left(\mathrm{AlO}_{2}\right)_{\mathrm{x}} \cdot\left(\mathrm{SiO}_{2}\right)_{\mathrm{y} \cdot \mathrm{x}} \mathrm{H}_{2} \mathrm{O}$. Struktur zeolit sejauh ini diketahui bermacam-macam, tetapi secara garis besar strukturnya terbentuk dari unit bangun primer, berupa tetrahedral yang kemudian menjadi unit bangun sekunder polihedral dan membentuk polihendra dan akhirnya unit struktur zeolit. Sifat zeolit sebagai adsorben dan penyaring molekul, dimungkinkan karena struktur zeolit yang berongga, sehingga zeolit mampu menyerap sejumlah besar molekul yang berukuran lebih kecil atau sesuai dengan ukuran rongganya. Selain itu kristal zeolit yang telah terdehidrasi merupakan adsorben yang selektif dan mempunyai efektivitas adsorpsi yang tinggi. 


\section{Penurunan (removal) Besi ( $\mathrm{Fe}$ ) dan Mangan} (Mn) dengan Filtrasi Kontak

Air baku yamg mengandung besi dan mangan dialirkan melalui suatu filter bed yang media filternya terdiri dari mangan-zeolite $\left(\mathrm{K}_{2} \mathrm{Z} . \mathrm{MnO} . \mathrm{Mn}_{2} \mathrm{O}_{7}\right)$. Mangan Zeolit berfungsi sebagai katalis dan pada waktu yang bersamaan besi dan mangan yang ada dalam air teroksidasi menjadi bentuk ferri-oksida dan mangandioksida yang tak larut dalam air.

Reaksinya adalah sebagai berikut :

$\mathrm{K}_{2} \mathrm{Z} \cdot \mathrm{MnO} \cdot \mathrm{Mn}_{2} \mathrm{O}_{7}+4 \mathrm{Fe}\left(\mathrm{HCO}_{3}\right)_{2}====>\mathrm{K}_{2} \mathrm{Z}$ $+3 \mathrm{MnO}_{2}+2 \mathrm{Fe}_{2} \mathrm{O}_{3}+8 \mathrm{CO}_{2}+4 \mathrm{H}_{2} \mathrm{O}$

$\mathrm{K}_{2} \mathrm{Z} \cdot \mathrm{MnO} \cdot \mathrm{Mn}_{2} \mathrm{O}_{7}+2 \mathrm{Mn}\left(\mathrm{HCO}_{3}\right)_{2}===>\mathrm{K}_{2} \mathrm{Z}+$ $5 \mathrm{MnO}_{2}+4 \mathrm{CO}_{2}+2 \mathrm{H}_{2} \mathrm{O}$

Reaksi penghilangan besi dan mangan dengan mangan zeoite tidak sama dengan proses pertukaran ion, tetapi merupakan reaksi dari $\mathrm{Fe}^{2+}$ dan $\mathrm{Mn}^{2+}$ dengan oksida mangan tinggi (higher mangan oxide).

Filtrat yang terjadi mengandung mengandung ferri-oksida dan mangandioksida yang tak larut dalam air dan dapat dipisahkan dengan pengendapan dan penyaringan. Selama proses berlangsung kemampunan reaksinya makin lama makin berkurang dan akhirnya menjadi jenuh. Untuk regenerasinya dapat dilakukan dengan menambahkan larutan Kaliumpermanganat kedalam zeolite yang telah jenuh tersebut sehingga akan terbentuk lagi mangan zeolite $\left(\mathrm{K}_{2} \mathrm{Z} . \mathrm{MnO} \cdot \mathrm{Mn}_{2} \mathrm{O}_{7}\right)$ (Idaman Said, Nusa, 1999).

\section{Karakteristik Resin/Ion Exchange}

Resin pertukaran asam kuat mengandung gugus fungsional yang diturunkan dari asam kuat (biasanya asam sulfat). Resin pertukaran asam lemah mengandung gugus fungsional yang diturunkan dari asam lemah (umumnya bentuk karboksilat atau fenolat).Resin pertukaran basa kuat mengandung gugus fungsional yang berasal dari gugus ammonium kuarterner tipe I dan II, sedangkan resin pertukaran basa lemah mengandung amina primer, sekunder, dan/atau tersier sebagai gugus fungsional.

\section{METODOLOGI}

Untuk mencapai tujuan penelitian ini, maka tahapan kegiatan yang dilakukan adalah studi literatur berupa kajian tinjauan penelitian terdahulu, penelitian yang akan dikerjakan, rancangan penelitian: berupa kerangka penelitian, kriteria desain, persiapan penelitian. Adapun pelaksanaan penelitian meliputi pengolahan data, analisis menurut kriteria parameter air bersih untuk sampel air tanah, dan penentuan nilai removal hasil treatment. Rancangan penelitian ini seperti pada gambar 1 .

\section{Rancangan (Kriteria) Desain}

Model desain reactor penelitian menggunakan tabung housing filter dan tabung Fiber Reinforced Plastic (FRP), dimana treatment yang dilakukan adalah ; Ferrolite, Manganese Zeolite, dan Ion Exchangese bagaimana rangkaian gambar 2 . 


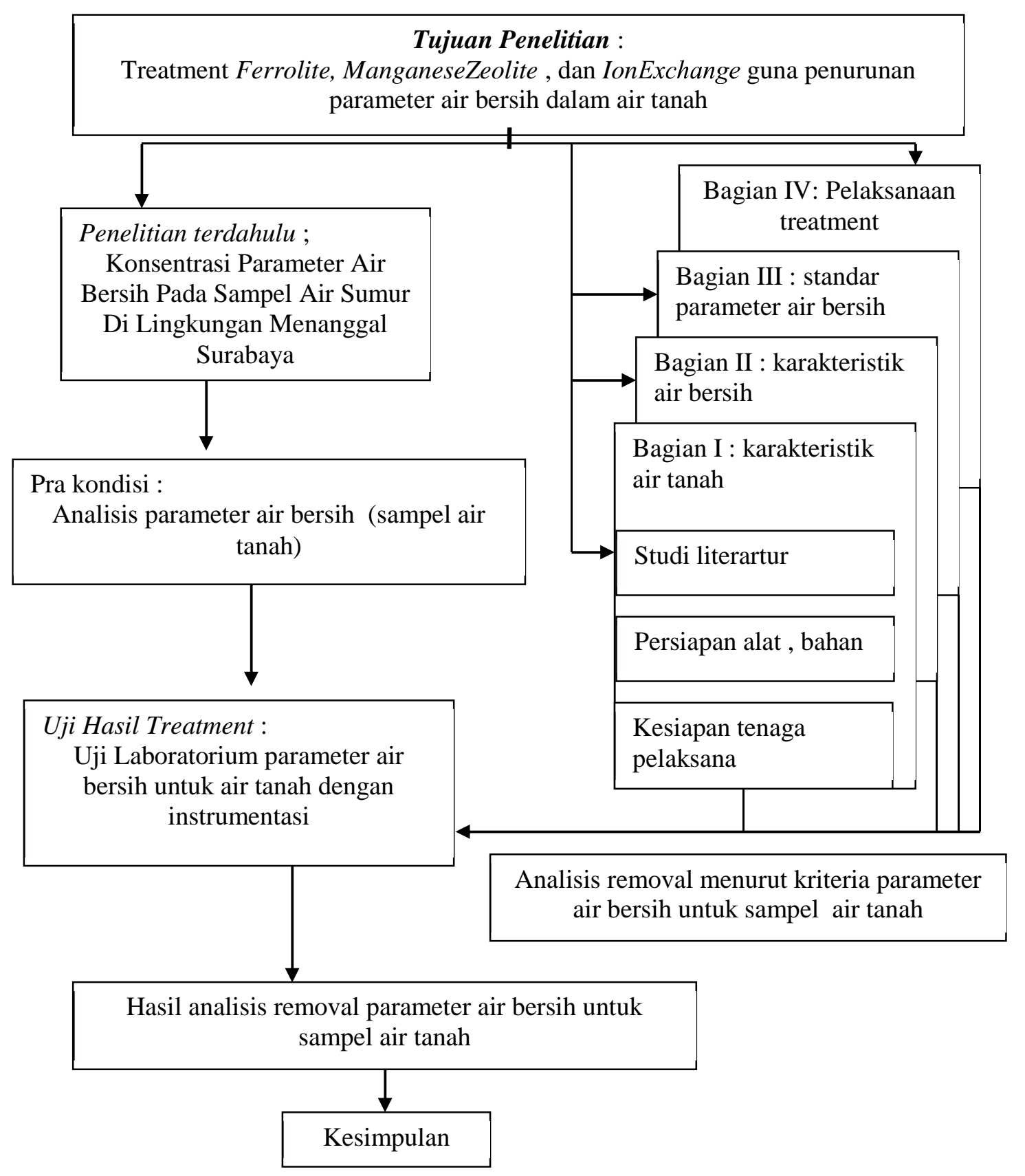

\section{Gambar 1. Alur Rancangan Penelitian}




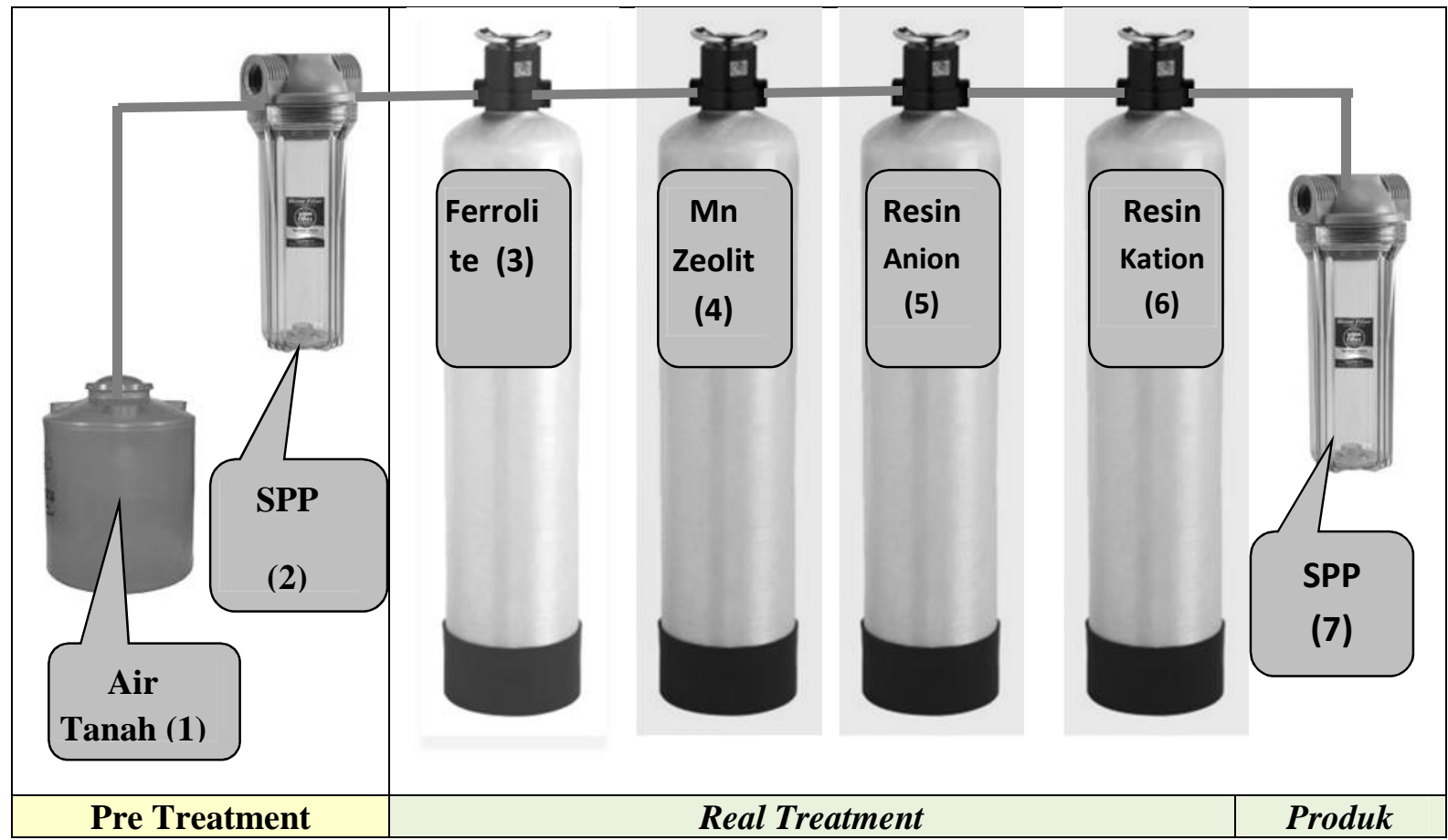

Keterangan Gambar 2:

\section{Gambar 2. Model Desain Reactor Penelitian}

(1) = Air tanah sebagai Air baku olahan

(2) $=$ Sediment Polypropylene (SPP) dalam tabung housing filter

(3) $=$ treatment Ferrolite pada tabung FRP

(4) = treatmentManganese Zeolitpada tabung FRP

(5) = treatment resin anion pada tabung FRP

(6) $=$ Treatment resin kation pada tabung FRP

(7) = Sediment Polypropylene (SPP) sebagai filter produk

Alur (Prosedur) Proses Pengolahan

Proses pengolahan bahan baku air tanah diawali dengan filtrasi menggunakan Sediment Polypropylene (SPP) dalam tabung housing filter (2), kemudian treatment Ferrolite pada tabung FRP (3). Selanjutnya berturut turut treatment ; Manganese Zeolitpada tabung FRP (4), resin anion pada tabung FRP (5), dan resin kation pada tabung FRP (6). Sebagai finishing treatment adalah Sediment Polypropylene (SPP) sebagai filter produk (7)

\section{Pengumpulan Data}

Hasil treatment dilakukan uji laboratorium yang mengacu pada kriteria parameter Air Bersih menurut baku mutu PERMENKES RI No. : 416 MENKES/PER/IX/90, dimana untuk parameter kekeruhan menggunakan metode analisis turbidimetri, warna menggunakan spektrofotometri, kandungan zat besi menggunakan spektrofotometri, kromium menggunakan AAS, dan Mn menggunakan spektrofotometri.
Analisis Data

Tahapan pengolahan data meliputi kegiatan koreksi keberhasilan removal kation anion sebelum dan setelah treatment, dan evaluasi terpadu dimensi reaktor dan fenomena kapasitas demineralisasi

\section{HASIL DAN PEMBAHASAN}

Hasil

Pengolahan air dalam penelitian ini menggunakan treatment Ferrolite, Manganese Zeolite, dan Ion exchanger berupa resin anion dan resin kation, dimana uji laboratorium dilakukan untuk sampel hasil pengolahan.

Uji laboratorium ini dilakukan guna mengetahui seberapa besar penurunan ( $\%$ removal) parameter parameter kation dan anion yang terkandung dalam air baku setelah dilakukan treatment. Hal ini akan berkontribusi dalam pembahasan tentang kemampuan kinerja treatment Ferrolite, 
Manganese Zeolite, dan Ion exchanger berupa resin anion dan resin kation dalam hal penjernihan air. Adapun rekap hasil uji yang mengacu pada kualitas air bersih dan air minum serta removal disajikan pada Tabel 1 .

Tabel 1. Rekap Data Hasil Uji Laboratorium

\begin{tabular}{|c|c|c|c|c|c|c|c|}
\hline No & Parameter & Satuan & $\begin{array}{c}\text { Syarat Air } \\
\text { Bersih*) }\end{array}$ & $\begin{array}{c}\text { Syarat Air } \\
\text { Minum*) }\end{array}$ & $\begin{array}{c}\text { Air Baku } \\
\text { (sampel) }\end{array}$ & $\begin{array}{c}\text { Treatment } \\
\text { Ferrolite, } \\
\text { MGS, dan } \\
\text { Resin } \\
\end{array}$ & Removal \\
\hline \multicolumn{3}{|c|}{ A. FISIKA } & & & & & \\
\hline 1 & Bau & - & tak berbau & - & Tak berbau & Tak Berbau & \\
\hline 2 & $\begin{array}{l}\text { Total Disolved } \\
\text { Solid (TDS) }\end{array}$ & $\mathrm{mg} / \mathrm{L}$ & 1500 & 500 & 558 & 538 & 20.00 \\
\hline 3 & Kekeruhan & Skala NTU & 25 & 5 & 31.2 & 0.84 & 30.36 \\
\hline 4 & Rasa & - & tak berasa & - & - & - & \\
\hline 5 & Suhu & $\mathrm{oC}$ & $\begin{array}{l}\text { suhu udara } \\
\pm 3^{\circ} \mathrm{C}\end{array}$ & Suhu Udara & 25 & 25 & 0.00 \\
\hline 6 & Warna & Unit PtCo & 50 & 15 & 130 & 10 & 120.00 \\
\hline \multicolumn{3}{|c|}{ B. KIMIA } & & & & & \\
\hline \multicolumn{3}{|c|}{ a. Kimia Anorganik } & & & & & \\
\hline 1 & Air Raksa & $\mathrm{mg} / \mathrm{L} \mathrm{Hg}$ & 0.001 & 0,001 & 0 & 0 & 0.00 \\
\hline 2 & Arsen & $\mathrm{mg} / \mathrm{L}$ As & 0.05 & 0,01 & 0 & 0 & 0.00 \\
\hline 3 & Besi & $\mathrm{mg} / \mathrm{L} \mathrm{Fe}$ & 1 & 0,3 & 2.54 & 0.12 & 2.42 \\
\hline 4 & Fluorida & $\mathrm{mg} / \mathrm{L} \mathrm{F}$ & 1.5 & 1,5 & 0.62 & 0.61 & 0.01 \\
\hline 5 & Kadmium & $\mathrm{mg} / \mathrm{L} \mathrm{Cd}$ & 0.005 & 0,003 & 0 & 0 & 0.00 \\
\hline 6 & $\begin{array}{l}\text { Kesadahan } \\
\text { Total }\end{array}$ & $\mathrm{mg} / \mathrm{L} \mathrm{CaCO} 3$ & 500 & 500 & 385.71 & 164.28 & 221.43 \\
\hline 7 & Khlorida & $\mathrm{mg} / \mathrm{L} \mathrm{Cl}$ & 600 & 250 & 100 & 232 & -132.00 \\
\hline 8 & $\begin{array}{l}\text { Kromium, Val } \\
\text { VI }\end{array}$ & $\mathrm{mg} / \mathrm{L} \mathrm{Cr}$ & 0.05 & 0,05 & 38.17 & 0 & 38.17 \\
\hline 9 & Mangan & $\mathrm{mg} / \mathrm{L} \mathrm{Mn}$ & 0.5 & 0,4 & 6.18 & 0 & 6.18 \\
\hline 10 & Nitrat & $\begin{array}{c}\mathrm{mg} / \mathrm{L} \\
\mathrm{NO3}-\mathrm{N}\end{array}$ & 10 & 50 & 0.13 & 1.07 & -0.94 \\
\hline 11 & Nitrit & $\begin{array}{c}\mathrm{mg} / \mathrm{L} \\
\mathrm{NO} 2-\mathrm{N}\end{array}$ & 1 & 3 & 0.087 & 0.03 & 0.06 \\
\hline 12 & $\mathrm{pH}$ & - & $6,5-9,0$ & $6,5-8,5$ & 6.95 & 8.8 & -1.85 \\
\hline 13 & Selenium & $\mathrm{mg} / \mathrm{L} \mathrm{Se}$ & 0.01 & 0,01 & 0 & 0 & 0.00 \\
\hline 14 & Seng & $\mathrm{mg} / \mathrm{L} \mathrm{Zn}$ & 15 & 3 & 0.09 & 0.07 & 0.02 \\
\hline 15 & Sianida & $\mathrm{mg} / \mathrm{L} \mathrm{CN}$ & 0.1 & 0,07 & 0 & 0 & 0.00 \\
\hline 16 & Sulfat & $\mathrm{mg} / \mathrm{L} \mathrm{SO} 4$ & 400 & 250 & 38.17 & 17 & 21.17 \\
\hline 17 & Timbal & $\mathrm{mg} / \mathrm{L} \mathrm{Pb}$ & 0.05 & 0,01 & 0 & 0 & 0.00 \\
\hline \multicolumn{3}{|c|}{ b. Kimia Organik } & & & & & \\
\hline 1 & Zat Organik & mg/L KMnO4 & 10 & 10 & 7.58 & 20.86 & -13.28 \\
\hline 2 & Detergent & $\mathrm{mg} / \mathrm{L}$ LAS & 0.5 & 0,05 & 0.05 & 0.03 & 0.02 \\
\hline
\end{tabular}

Pembahasan

Hasil analisis kriteria parameter air bersih untuk sampel air tanah didasarkan pada parameter setelah dilakukan treatment Ferrolite, ManganeseZeolite, dan Ion exchanger berupa resin anion dan resin kation didapatkan temuan temuan sebagai berikut :

Mengacu pada Tabel 1., tampak bahwa kandungan Kromium Val (VI) dalam air sampel sangat tinggi (yaitu $38.17 \mathrm{mg} / \mathrm{L} \mathrm{Cr}$ ), jauh lebih besar dibanding dengan baku mutu air bersih (hanya 0.05). Hal ini menjadikan air baku tidak layak sebagai air bersih. Kadar Krom yang berlebihan dapat mengakibatkan gangguan pencernaan, keracunan, bahkan kerusakan ginjal dan system syaraf.

Tinjauan menurut parameter air baku yang melebihi nilai baku mutu, tampak bahwa ; kekeruhan, warna, Besi, Kromium (VI), dan Mangan kesemuanya jauh lebih tinggi dibanding dengan nilai ambang batas yang diijinkan sebagai air bersih (Tabel 2.). Dari segi kesehatan, anak-anak yang terpapar konsentrasi Mangan tinggi dalam air minum dapat mengalami gangguan intelektual. 
Tabel 2. Parameter pada Air Baku yang Melebihi Nilai Baku Mutu sebagai Air Bersih.

\begin{tabular}{lccccc}
\hline No & Parameter & Satuan & $\begin{array}{c}\text { Syarat Air } \\
\text { Bersih*) }\end{array}$ & $\begin{array}{c}\text { Syarat Air } \\
\text { Minum*) }\end{array}$ & Air Baku \\
\hline 1. & Kekeruhan & Skala NTU & 25 & 5 & 31.2 \\
2. & Warna & Unit PtCo & 50 & 15 & 130 \\
3. & Besi & mg/L Fe & 1 & 0,3 & 2.54 \\
4. & Kromium (VI) & mg/L Cr & 0.05 & 0,05 & 38.17 \\
5. & Mangan & mg/L Mn & 0.5 & 0,4 & 6.18 \\
\hline
\end{tabular}

Menurut Tabel 2. parameter nomor 1 hingga 5 (kekeruhan, warna, Besi, Kromium (VI), dan Mangan) kesemuanya menunjukkan bahwa sampel ini tidak aman dikonsumsi sebagai air bersih.
Treatment Ferrolite, ManganeseZeolite, dan Ion exchange berupa resin anion dan resin kation dalam penelitian ini meremoval sebanyak 12 item parameter yang mengacu pada air bersih, disajikan pada Tabel 3. dan Gambar 3.

Tabel 3. Removal Parameter Air Bersih Hasil Treatment Ferrolite, MGS , dan Resin

\begin{tabular}{llcccccc}
\hline No & Parameter & Satuan & $\begin{array}{c}\text { Syarat Air } \\
\text { Bersih*) }\end{array}$ & $\begin{array}{c}\text { Syarat } \\
\text { Air } \\
\text { Minum*) }\end{array}$ & $\begin{array}{c}\text { Air } \\
\text { Baku }\end{array}$ & $\begin{array}{c}\text { Treatment } \\
\text { Ferrolite, } \\
\text { MGS , dan } \\
\text { Resin }\end{array}$ & Removal \\
\hline 1 & Total & mg/L & 1500 & 500 & 558 & 538 & 20.00 \\
& $\begin{array}{l}\text { Disolved } \\
\text { Solid (TDS) }\end{array}$ & & & & & \\
2 & Kekeruhan & Skala NTU & 25 & 5 & 31.2 & 0.84 & 30.36 \\
3 & Warna & Unit PtCo & 50 & 15 & 130 & 10 & 120.00 \\
4 & Besi & mg/L Fe & 1 & 0,3 & 2.54 & 0.12 & 2.42 \\
5 & Fluorida & mg/L F & 1.5 & 1,5 & 0.62 & 0.61 & 0.01 \\
6 & Kesadahan & mg/L CaCO3 & 500 & 500 & 385.71 & 164.28 & 221.43 \\
& Total & mg/L Cr & 0.05 & 0,05 & 38.17 & 0 & 38.17 \\
7 & Kromium, & mol & & & & & \\
& Val VI & mg/L Mn & 0.5 & 0,4 & 6.18 & 0 & 6.18 \\
8 & Mangan & mg/L & 1 & 3 & 0.087 & 0.03 & 0.06 \\
9 & Nitrit & NO2-N & & & & & \\
& & mg/L Zn & 15 & 3 & 0.09 & 0.07 & 0.02 \\
10 & Seng & mg/L SO4 & 400 & 250 & 38.17 & 17 & 21.17 \\
11 & Sulfat & mg/L LAS & 0.5 & 0,05 & 0.05 & 0.03 & 0.02 \\
\hline 12 & Detergent & & & & & & \\
\hline
\end{tabular}

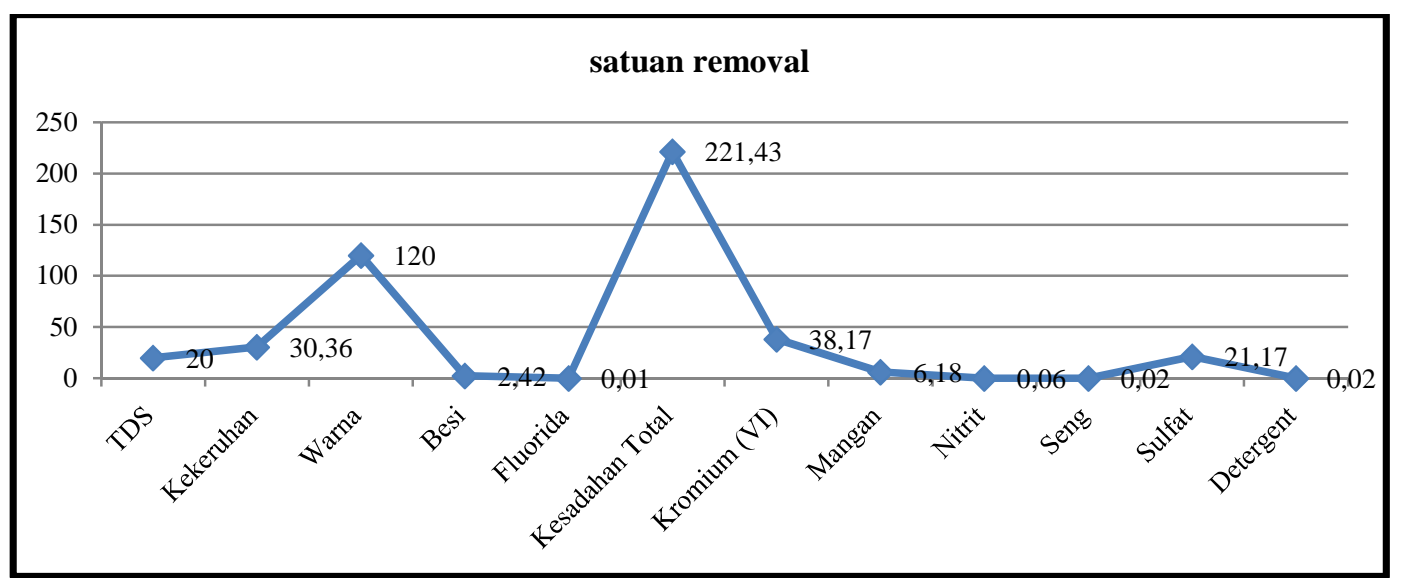

Gambar 3. Satuan Removal Parameter Oleh Kinerja Treatment 
Kemampuan kinerja treatment Ferrolite, ManganeseZeolite, dan Ion exchange berupa resin anion dan resin kation menurut Tabel 3. dan Gambar 3., mampu menurunkan parameter parameter fisik, kimia, dan detergen.

Kandungan Kromium sebesar 38.17 (mg/L $\mathrm{Cr})$ dan Mangan sebesar 6.18 (mg/L Mn) (yang keduanya merupakan logam berat) sangat tidak disarankan untuk criteria air bersih. Akan tetapi dengan treatment dalam penelitian ini mampu menurunkan kedua parameter tersebut hingga zero (nol).

Tabel 3. dan Gambar 3, memberikan gambaran bahwa telah banyak penurunan parameter parameter acuan air bersih hasil kinerja treatmen dalam penelitian ini. Namun jika dibandingkan dengan adanya tambahan perlakuan ReverseOsmosis(RO), penurunan beberapa parameter masih lebih rendah dibandingnya. Hal ini dijumpai pada (Purwoto, S. at al., 2014) dinyatakan bahwa Treatment: SedimentPoly Propylene,CarbonBlock, Manganese Zeolite,Ion Exchange, and Reverse Osmosis(RO) can meett here quirements as clean waterisable toreduce some parameters (amount); Total Disolved Solid (TDS) 2686 ppm, Hardness Total $371.43 \mathrm{mg} / \mathrm{LCaCO} 3$, Zinc $0.08 \mathrm{ppm}$, Sulfate $24.56 \mathrm{ppm}$, and Detergent $0.10 \mathrm{mg} / \mathrm{LLAS}$. Akan tetapi untuk Besi, hasil penurunannya masih lebih tinggi dalam penelitian in (sebesar $2.42 \mathrm{mg} / \mathrm{L} \mathrm{Fe}$ ) dibanding dengan $0.18 \mathrm{mg} / \mathrm{L} \quad \mathrm{Fe}$ dalam Purwoto, S. at al., (2014).

Menurut Nurhayati, I, (2014), Kapasitas removal Besi dengan menggunakan perpaduan treatmen coagulantaid, Filtrasi sediment polipropylena (SPP), dan absorsi manganese greens and, dilanjutkan dengan Ion Exchanger sebesar 0.22 ppm,lebih kecil dibandingkan dengan removal hasil penelitian ini (sebesar $2.42 \mathrm{mg} / \mathrm{L} \mathrm{Fe}$ ).

Temuan Sugito (2014), dalam pengolahan air berbasis membrane permiabel Ion Exchange yang dikombinasikan dengan Electrodeionization (EDI) diperoleh nilai penurunan: Total Disolved Solid (TDS) 752 ppm, kesadahan $457.24 \mathrm{mg} / \mathrm{LCaCO} 3$, Nitrit $0.49 \mathrm{mg} / \mathrm{L}$ NO2-N, Seng $0.07 \mathrm{ppm}$, dan Detergent 0:06mg/LLAS (lebih tinggi dibanding dengan hasil penelitian ini). Dalam hal removal kekeruhan, warna, Besi, dan sulfat dalam penelitian ini hasilnya lebih besar disbanding dengan Sugito, (2014) yaitu ; kekeruhan4.94 skala NTU, warna 40 unit PtCo, Besi $0.55 \mathrm{mg} / \mathrm{L} \mathrm{Fe}$, dan Sulfat 9.14 ppm.

Merujuk pada perbandingan terhadap temuan pada ketiga jurnal di atas, tentang penurunan zat Besi dalam penelitian ini hasilnya lebih besar. Hal ini dimungkinkan karena adanya treatment ferrolite sebagaimana diperlakukan dalam penelitian ini, dan tidak digunakan dalam perlakuan pada ketiga jurnal tersebut.

Ditinjau dari persentase tingkat removal, pada Tabel 4. tampak bahwa parameter : Kekeruhan, Warna, Besi, Kromium (VI), dan Mangan sangat signifikan, bahkan untuk Kromium (VI) dan Mangan hingga mencapai $100 \%$.

Tabel 4. Persentase Removal Parameter Air Bersih Hasil Treatment Ferrolite, MGS , dan Resin

\begin{tabular}{lllllll}
\hline No & Parameter & $\begin{array}{c}\text { Syarat Air } \\
\text { Bersih *) }\end{array}$ & Air Baku & Treatment & Removal & $\begin{array}{c}\% \\
\text { Removal }\end{array}$ \\
\hline 1 & TDS & 1500 & 558 & 538 & 20.00 & $\mathbf{3 . 6}$ \\
2 & Kekeruhan & 25 & 31.2 & 0.84 & 30.36 & $\mathbf{9 7 . 3}$ \\
3 & Warna & 50 & 130 & 10 & 120.00 & $\mathbf{9 2 . 3}$ \\
4 & Besi & 1 & 2.54 & 0.12 & 2.42 & $\mathbf{9 5 . 3}$ \\
5 & Fluorida & 1.5 & 0.62 & 0.61 & 0.01 & $\mathbf{1 . 6}$ \\
6 & Kesadahan Total & 500 & 385.71 & 164.28 & 221.43 & $\mathbf{5 7 . 4}$ \\
7 & Kromium (VI) & 0.05 & 38.17 & 0 & 38.17 & $\mathbf{1 0 0 . 0}$ \\
8 & Mangan & 0.5 & 6.18 & 0 & 6.18 & $\mathbf{1 0 0 . 0}$ \\
9 & Nitrit & 1 & 0.087 & 0.03 & 0.06 & $\mathbf{6 5 . 5}$ \\
10 & Seng & 15 & 0.09 & 0.07 & 0.02 & $\mathbf{2 2 . 2}$ \\
11 & Sulfat & 400 & 38.17 & 17 & 21.17 & $\mathbf{5 5 . 5}$ \\
12 & Detergent & 0.5 & 0.05 & 0.03 & 0.02 & $\mathbf{4 0 . 0}$ \\
\hline
\end{tabular}


Kondisi kemampuan removal ini sangat menguntungkan, karena Kromium (VI) dan Mangan merupakan logam berat yang sangat berbahaya dalam mengkonsumsi air. Senyawa Besi dalam jumlah kecil di dalam tubuh manusia berfungsi sebagai pembentuk sel-sel darah merah, dimana tubuh memerlukan 7-35 $\mathrm{mg} / \mathrm{hari}$ yang sebagian diperoleh dari air. Tetapi zat Fe yang melebihi dosis yang diperlukan oleh tubuh dapat menimbulkan masalah kesehatan. Hal ini dikarenakan tubuh manusia tidak dapat mengsekresi Fe, sehingga bagi mereka yang sering mendapat tranfusi darah warna kulitnya menjadi hitam karena akumulasi Fe. Air minum yang mengandung besi cenderung menimbulkan rasa mual apabila dikonsumsi. Selain itu dalam dosis besar dapat merusak dinding usus. Kematian sering kali disebabkan oleh rusaknya dinding usus ini. Kadar Fe yang lebih dari $1 \mathrm{mg} / \mathrm{l}$ akan menyebabkan terjadinya iritasi pada mata dan kulit. Apabila kelarutan besi dalam air melebihi $10 \mathrm{mg} / \mathrm{l}$ akan menyebabkan air berbau seperti telur busuk.

Jika ditinjau dari trend removal oleh kemampuan treatment untuk parameter pada air baku yang melebihi nilai baku mutu sebagai air bersih tampak bahwa parameter kekeruhan, warna, Besi, Kromium (VI), dan Mangan mampu diremoval secara baik, bahkan untuk Kromium (VI), dan Mangan mencapai $100 \%$ (Gambar 4.)

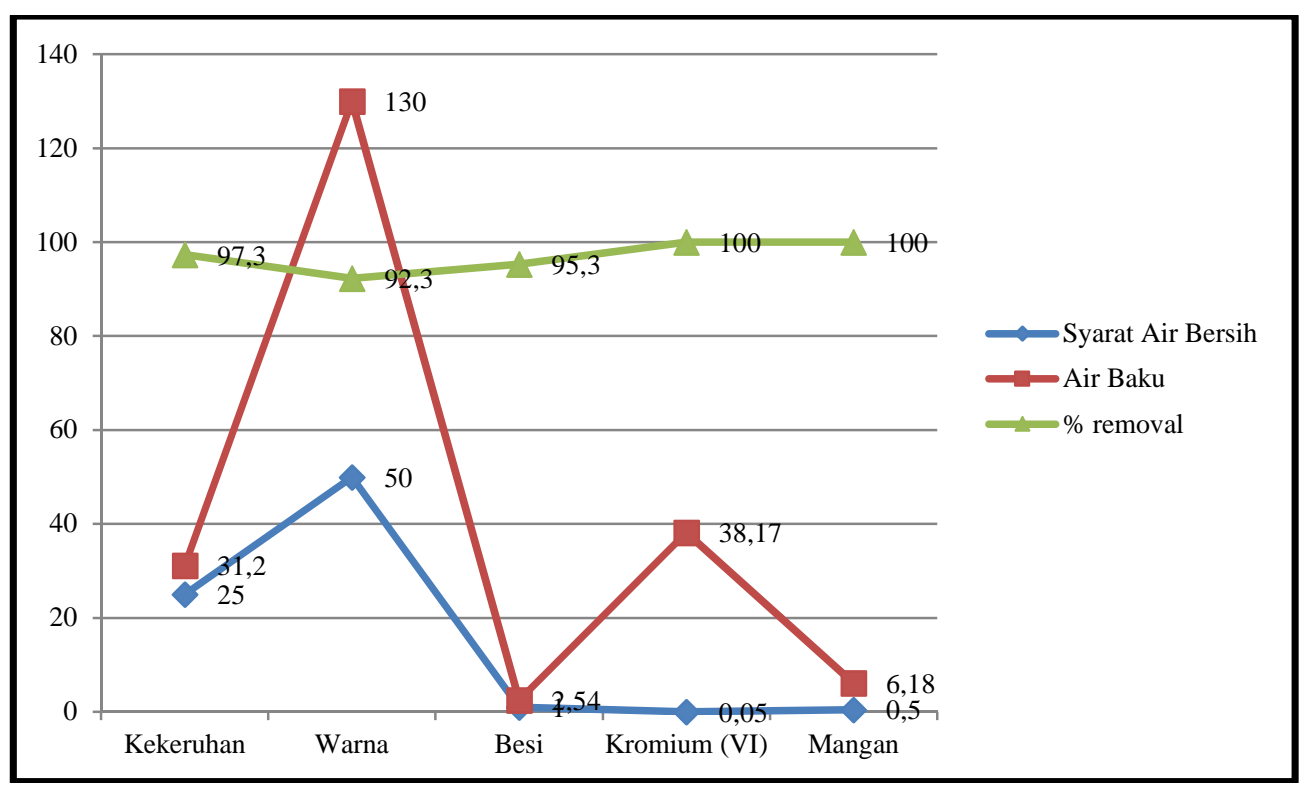

\section{Gambar 4. Trend Removal Oleh Kemampuan Treatment Untuk Parameter Pada Air Baku Yang Melebihi Nilai Baku Mutu Sebagai Air Bersih.}

\section{KESIMPULAN}

Treatment ferrolite, manganese zeolite, dan ion exchanger berupa resin anion dan resin kation pada air tanah mampu meremoval kandungan beban kekeruhan, warna, dan logam logam Besi, Kromium, serta Mangan hingga menjadi kriteria parameter air bersih mengacu pada permenkes nomor 416/Menkes/Per/IX/1990.

\section{UCAPAN TERIMA KASIH}

Ucapan terima kasih kepada Universitas PGRI Adi Buana Surabaya yang telah membiayai penelitian ini melalui Lembaga Penelitian dan Pengabdian pada Masyarakat.

\section{DAFTAR PUSTAKA}

Idaman Said, Nusa, (1999). Direktorat Tehnologi Lingkungan. BPPT, Jakarta. Indonesia,Permenkes.(1990). Persyaratan Air Bersih, Nomor;416/Menkes/Per/IX/1990 Kusnaedi. (1995). Mengolah Air Gambut dan Air Kotor untuk Air Minum. Jakarta:Penebar Swadaya.

Montgomery, J.M., (2005). Water Treatment Principles and Design. Johan Weley Inc. USA 
Nurhayati, I., Purwoto, S. (2014). "The Combination of Coagulant Aid, Ion Exchanger, and Reverse Osmosis (RO ) on Brackish Water Treatment." Journal of Natural Sciences Research, ISSN 2224-3186 (Paper); ISSN 2225-0921 (Online) 4(24): 26-30.

Paten P00201404180. "Proses Pengolahan air menggunakan perpaduan zeolit, ion exchange,dan RO"

Purwoto, S., 2008. "Removal Salinitas Air Payau Secara Ion Exchange DenganTreatment Resin Sintetis Pada Reaktor Up-Flow Down-Flow" ; Prosiding ISBN ;978-979-97071-8-5 DP2MDIKTI-ITS Surabaya, SEMINAR NASIONAL HASIL PDM - SKW, 16-18 Desember 2008.

Purwoto, S., (2009). "Alat Desalinasi Air Payau Secara Ion Exchange Menggunakan Resin Sintetis" Paten - P00200900723

Purwoto, S. (2010). "Remove Capacity Treatment Zeolit Untuk Parameter Air Bersih"; Jurnal Sains "WAHANA" ISSN ;0853 - 4403, Vol 55 No 02 Ed. Des 2010

Purwoto, S. (2009). "Desalinasi Air Payau Secara Ion Exchange dengan Treatment Resin Sintetis." WAKTU ; ISSN : 1412-1867 Edisi Januari 2009 7(1): 52-59.

Purwoto, S. (2010). "Remove Capacity Treatment Zeolit Untuk Parameter Air Bersih." WAHANA ; ISSN : 0853-4403, ed.Agustus 2010 55(2): 63-70.

Purwoto, S., Sopandi, T., Kusuma, P.S.W., Nurcahyanie,W.D. (2014). "Removal Parameters of Clean Water using Treatment; Sediment Poly Propylene, Carbon Block, Manganese Zeolite, Ion Exchange, and Reverse Osmosis (RO)." Journal of Environment and Earth Science,_ISSN 2224-3216 (Paper) ISSN 2225-0948 (Online) 4(23): 72-77.

Rachmah, N., Purwoto, S. (2014). "Efektifitas Penurunan Mn dan Total Coliform Pada Air Sumur Gali Berbasis Zeolit." WAKTU,_ISSN : 1412-1867 , ed. Januari 2014 12(1): 1-7.

Sugito., Sembodo, B.P., (2014). "Water Treatment Based on Ion Exchange Membrane Permeable Combined with The Field Electrodeionization (EDI)." Civil and Environmental Research, ISSN (Paper) 2224-5790 ISSN (Online) 2225-05146 (12): 10-15. 